\title{
Study into Movement of Wide SPan Tractors (Vehicles) USED IN CONTROLled TrafFic FARMing
}

\author{
Volodymyr Bulgakov, Valerii Adamchuk, Volodymyr Kuvachov, \\ Margus Arak \& Jüri Olt
}
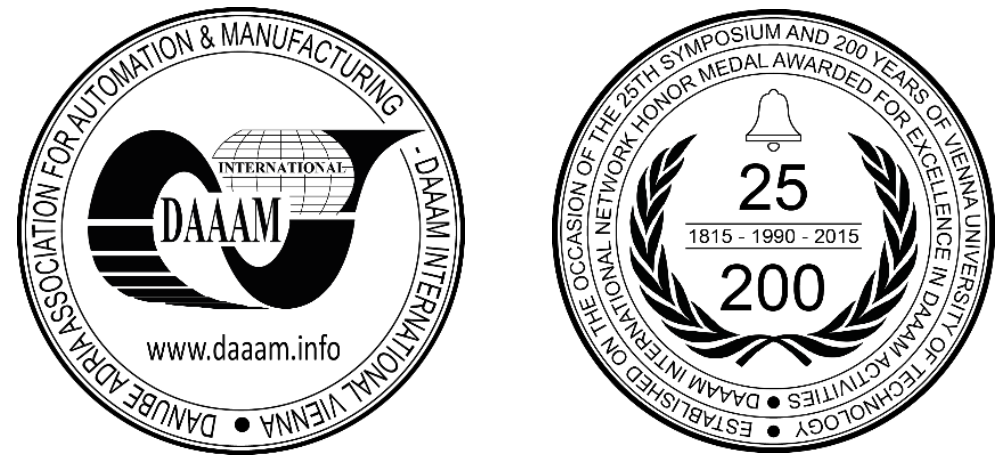

This Publication has to be referred as: Bulgakov, V[olodymyr]; Adamchuk, V[alerii]; Kuvachov, V[olodymyr]; Arak, M[argus] \& Olt, J[ueri] (2017). Study Into Movement of Wide Span Tractors (Vehicles) Used in Controlled Traffic Farming, Proceedings of the 28th DAAAM International Symposium, pp.0199-0208, B. Katalinic (Ed.), Published by DAAAM International, ISBN 978-3-902734-11-2, ISSN 1726-9679, Vienna, Austria DOI: $10.2507 / 28$ th.daaam.proceedings.027

\begin{abstract}
Wide span tractors/vehicles have good prospects as the mechanisation means for controlled traffic farming. The efficiency of the practical application of wide span tractors (vehicles) depends on the availability of the substantiated scientific basis or the theoretical basis for the research into their key properties, including among other factors the smoothness of movement. The aim of the research is to improve the smoothness of movement of wide span tractors (vehicles) by substantiating their configuration, design-and-process and other parameters as well as the properties of the longitudinal profile of the agricultural background irregularities in the ruts of the laid-down process track. The smoothness of movement of the wide span tractor (vehicle) as a dynamic system travelling in the ruts of the permanent process track substantially depends on the structure of the latter's longitudinal profile, the stiffness of tyres on the supporting wheels, while the dynamics of the vertical oscillations of the process section depends on its operating weight.
\end{abstract}

Keywords: wide span tractor (vehicle); smoothness; movement; dynamic system

\section{Introduction}

One of the ways to improve the cultural and technological level of farming is to arrange the strictly controlled (routed) traffic of all mechanical means only on specially preformed paths - permanent process tracks [1-3] and [16-19]. Their implementation facilitates the resolution of the contradiction that exists in the "running gear - soil" system. The physical essence of it is in the fact that process and transport machines need for their travelling dry and firm ground (engineering zone of field), while the efficient growth of plants takes place on broken and humid soil (agronomical zone of field) [1, 4], [8-10] and [20].

It has been known that the reduction of the area of transport and process lanes and extension of the working width of agricultural units improves the land use indices in controlled traffic farming [5]. A substantial rise of efficiency in this context is achieved through the application of wide span tractors or wide span vehicles [6, 7] and [11, 12] designed specifically for controlled traffic farming (Fig. 1). 

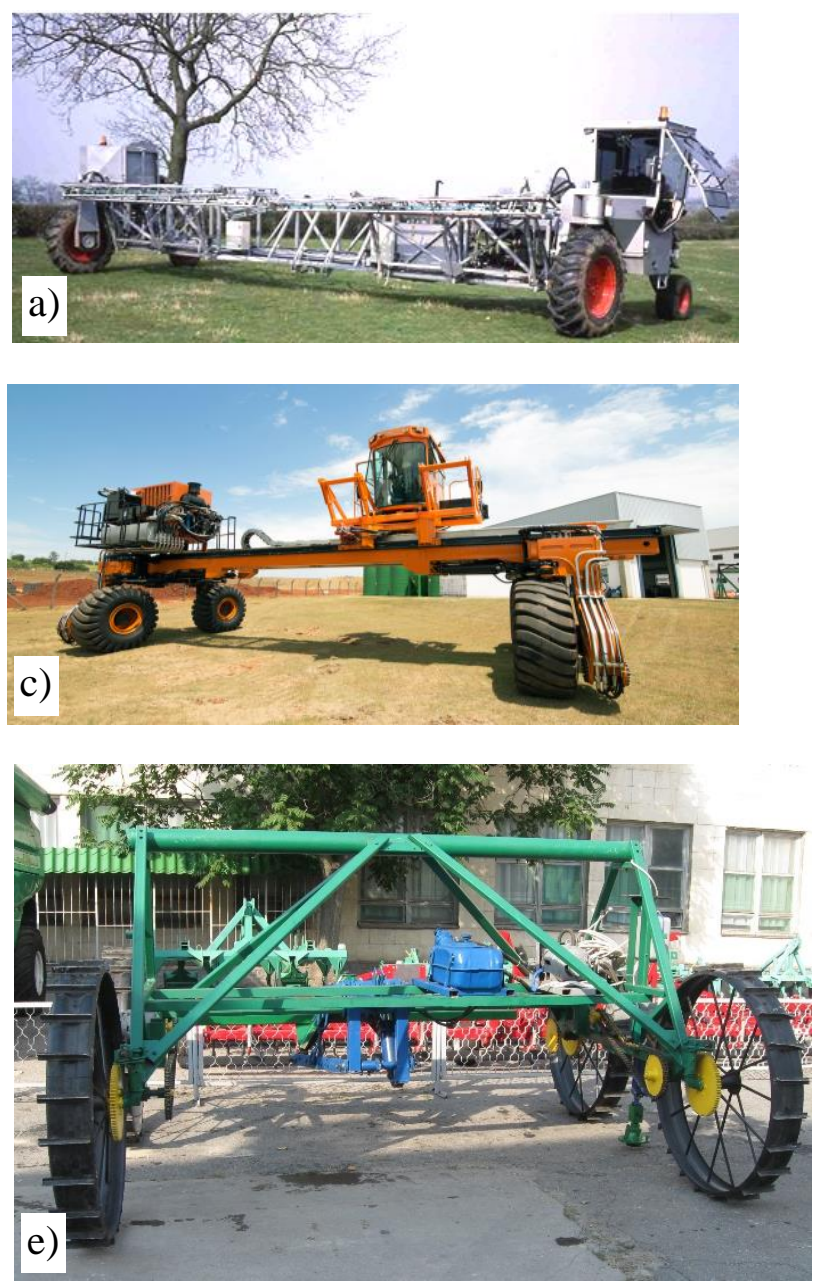
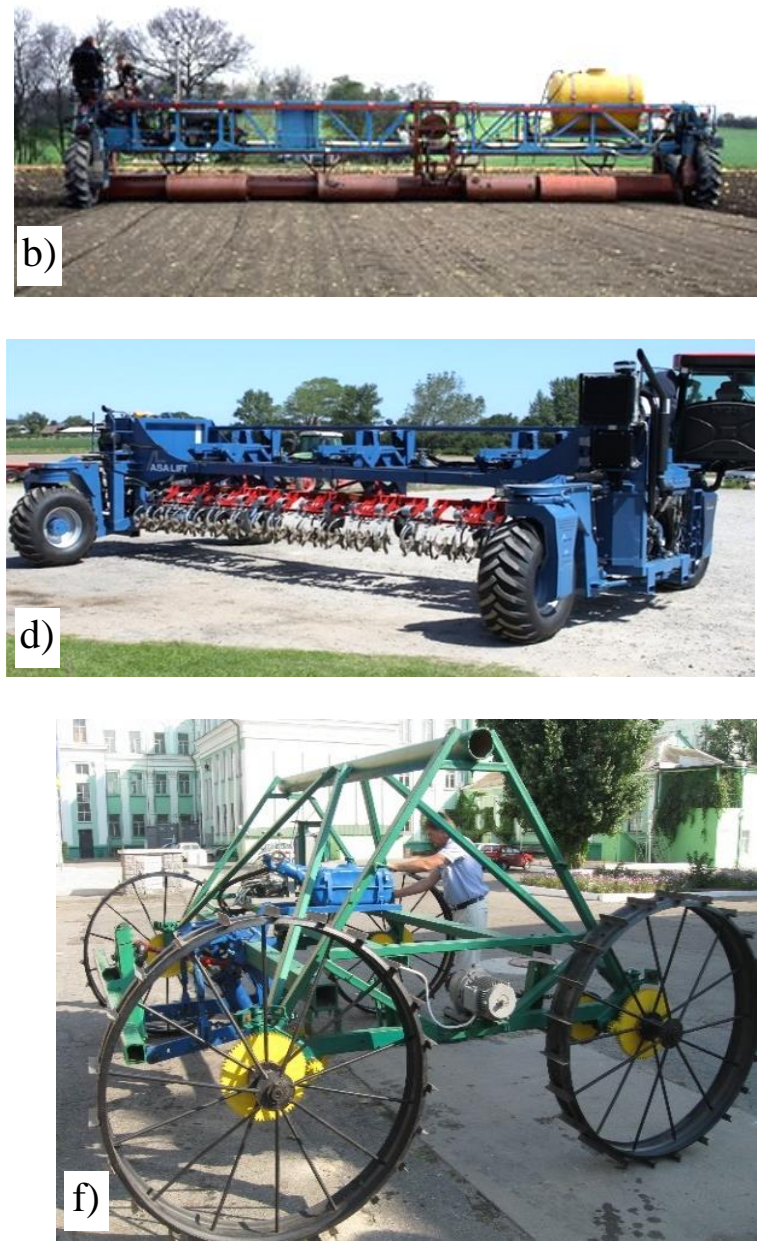

Fig. 1. Various designs of wide span tractors (vehicles) for controlled traffic farming: Dowler wide span tractor (a) and vehicle (b); ETC CTBE wide span tractor (c); ASA-Lift WS 9600 WS wide span tractor (d); wide span vehicles

Ukraine (e and f).

We assume that the subject matter of the theory of wide span tractor (vehicle) is the methods of determining its properties, including in particular the smoothness of movement.

Obviously, the dynamics of the movement of a wide span tractor (vehicle) in the vertical plane is defined by the perturbing input actions, which include the irregularities of the longitudinal profile of the permanent process track and the non-uniformity of the tractive resistance of the soil. Certainly, the internal structure characteristics of the longitudinal profile of the laid-down process track has an effect on the smoothness of movement of the wide span tractor (vehicle) and the fluctuation of its tractive force with all the negative implications.

As is known, the quality of some dynamic system's response to input variables depends on its characteristic properties. As regards the wide span tractor (vehicle), they include its configuration as well as its design and other parameters. Therefore, the correct selection of the latter with respect to the required smoothness of movement will ensure the optimal transformation by the machine of the perturbing actions that have an effect on it.

All the recognised studies on the discussed issue, for example [13-15] and [21] were aimed at the investigation of the dynamics of motion of the tractor-implement units built on the basis of conventional tractors, while the problem under consideration remained outside their scope of research. The accumulated scientific and practical experience of using conventional tractor-implement units in controlled traffic farming has facilitated the substantiation of certain requirements to the parameters of the permanent process track. Nevertheless, the said requirements do not take into account the atypical design layout of the wide span tractor (vehicle), its specific way of unitization and functioning conditions, therefore, they need adjustment. At the same time, the already established methods of selecting the structural layouts, parameters and modes of operation for tractor-implement units cannot be employed in the investigation of the dynamics of motion of wide span tractors in the vertical plane. Thereby, with regard to the efficient utilization of wide span tractors (vehicles) unresolved issues arise, which are concerned with research into the conditions stipulating their design and other parameters.

The objective of the research is to improve the smoothness of movement of wide span tractor (vehicle) by substantiating their configuration, design-and-process and other parameters as well as the properties of the longitudinal profile of the agricultural background irregularities in the ruts of the laid-down process track. 


\section{Materials and Methods}

The basis of the research is made up of the fundamental principles of the theoretical mechanics, the statistical dynamics, the theory of the automatic control of linear dynamic systems responding to statistically random perturbing input actions, the theory of tractor. The assessment of the effect that the design and the parameters of a wide span tractor (vehicle) have on the dynamics of its motion in the vertical plane is based on the analysis of the amplitude and phase frequency response characteristics, programme design and calculations with the use of the PC.

It is expedient to consider the functional model of the wide span tractor/vehicle as a dynamic system in the form of its reaction to the input perturbation, the characteristic of the response to which unequivocally determines the smoothness of movement. In this case the perturbations are represented by the shocks and impacts caused by the profile irregularities of the permanent process track and the variation of the tractive resistance created by the agricultural tools on the process section of the wide span tractor (vehicle). The behaviour of a particular dynamic system as regards its response to the input variables depends on its specific features. As applied to the wide span tractor, such specific features include its configuration, design, process, kinematic and other parameters. Hence, the adequate selection of the latter with respect to the desired stability of motion will ensure for the wide span tractor the optimal transformation of the perturbing actions it is under the effect of.

It has been known that the transformation properties of a dynamic system can be expressed in terms of transfer functions and frequency-response characteristics. Those characteristics are exactly what provides the most complete and physical notion of the reactions of the agricultural unit to various perturbations as well as the transient and stable processes of its operation.

For the theoretical analysis of the transfer functions and frequency-response characteristics, it is necessary to generate the system of corresponding differential equations relating the original variables to the input perturbations, i.e. the mathematical model of the process. At this stage of investigation, it is appropriate to consider it in the form of a linear equation system. Such idealisation will be rather efficient in this case, because the dynamics of motion of the wide span tractor has not yet been sufficiently well studied. While the knowledge of it will provide the capability to interpret physically the obtained results and accumulate the experience of designing.

In the process of solving the problems of optimisation of parameters of the linear stationary dynamic system, amplitude (AFR) and phase (PFR) frequency response characteristics will be used in the capacity of the operators. For this purpose, after generating the corresponding differential equations and formulating transfer functions on their basis, it is necessary to calculate and analyse the AFR and PFR for both the assumed input perturbations. The following provisions and assumptions will be adopted / made in order to simplify the generation of the differential equations: angular oscillations of the process part of the wide span tractor (vehicles) are ignored; variation of the tractive resistance of the agricultural implements has no effect on the velocity of the translational movement of the wide span tractor (vehicle), therefore, it is assumed to be constant; the permanent process track profile irregularities are described by a random ergodic stationary function of the covered distance; there is no inclination of the wide span tractor (vehicle) in the transverse-longitudinal plane; resistance forces in the carrying wheel tyres are assumed to be proportional to the velocity of oscillations, while the characteristics of elastic members - linear.

The actual wide span tractor (vehicle) can be represented by an equivalent dynamic model (Fig. 2) with three degrees of freedom: vertical displacement $\mathrm{z}_{\mathrm{T}}$ of the centre of mass $\left(\mathrm{S}_{\mathrm{T}}\right)$, angular oscillations of the body $\varphi_{\mathrm{T}}$ and vertical displacement $z_{3}$ of the centre of mass of the process section $\left(S_{\mathrm{p}}\right)$. The displacement $\mathrm{z}_{\mathrm{T}}$ and angular oscillations $\varphi_{\mathrm{T}}$ are related to the vertical displacements of the front and rear parts of the wide span tractor's (vehicles) body $\left(\mathrm{z}_{1}\right.$ and $\left.\mathrm{z}_{2}\right)$ (Fig. 2). Therefore, the vertical displacements $z_{1}, z_{2}$ and $z_{3}$ of the front and rear parts of the wide span tractor (vehicle) body and the body of the process section respectively will be considered as the generalised coordinates.

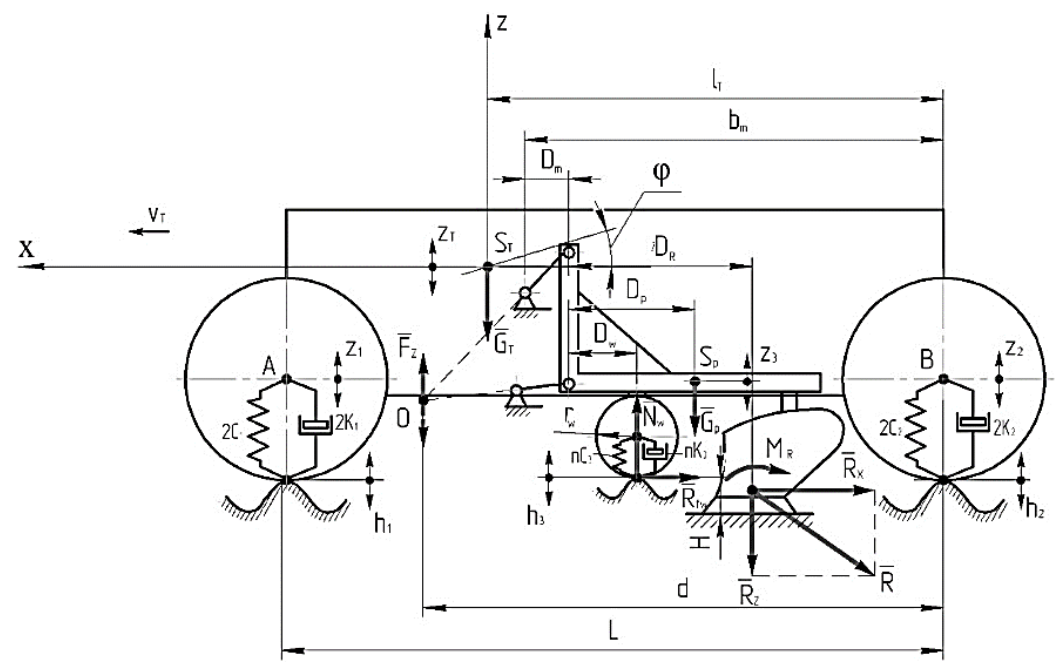

Fig. 2. Equivalent dynamic model of the wide span tractor (vehicle) 
The mathematical model of the plane parallel motion of a wide span tractor (vehicle) in the vertical-longitudinal plane developed on the basis of the Lagrange equations of the second kind will appear as follows:

$$
\left.\begin{array}{l}
\grave{A}_{11} \cdot \ddot{Z}_{1}+\grave{A}_{12} \cdot \dot{Z}_{1}+\grave{A}_{13} \cdot z_{1}+\grave{A}_{14} \cdot \ddot{z}_{2}=f_{11} \cdot \dot{h}_{1}+f_{12} \cdot h_{1}+f_{13} \cdot R_{\tilde{o}}+f_{14} \cdot R_{z}+f_{15} \cdot M_{R}+f_{16}, \\
\grave{A}_{21} \cdot \ddot{Z}_{2}+\grave{A}_{22} \cdot \dot{z}_{2}+\grave{A}_{23} \cdot z_{2}+\grave{A}_{24} \cdot \ddot{Z}_{1}=f_{21} \cdot \dot{h}_{2}+f_{22} \cdot h_{2}+f_{23} \cdot R_{\tilde{o}}+f_{24} \cdot R_{z}+f_{25} \cdot M_{R}+f_{26}, \\
\grave{A}_{31} \cdot \ddot{Z}_{3}+\grave{A}_{32} \cdot \dot{Z}_{3}+\grave{A}_{33} \cdot z_{3}=f_{31} \cdot \dot{h}_{3}+f_{32} \cdot h_{3}+f_{33} \cdot R_{\tilde{o}}+f_{34} \cdot R_{z}+f_{35} \cdot M_{R}+f_{36},
\end{array}\right\}
$$

where

$$
\begin{aligned}
& \grave{\mathrm{A}}_{11}=\left(\grave{\mathrm{I}}_{\mathrm{T}} \cdot \mathrm{l}_{\mathrm{T}}^{2}+\mathrm{J}_{\mathrm{T}}\right) / \mathrm{L}^{2} \text {; } \\
& \grave{A}_{12}=2 \hat{E}_{1} ; \quad \grave{A}_{13}=2 \tilde{N}_{1} \text {; } \\
& \grave{A}_{14}=2\left(\mathrm{I}_{\mathrm{T}} \cdot \mathrm{I}_{\mathrm{T}} \cdot\left(\mathrm{L}-\mathrm{I}_{\mathrm{T}}\right)-\mathrm{J}_{\mathrm{T}}\right) / \mathrm{L}^{2} \text {; }
\end{aligned}
$$

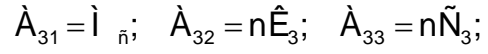

$$
\begin{aligned}
& \mathrm{f}_{11}=2 \hat{E}_{1} ; \quad \mathrm{f}_{12}=2 \tilde{N}_{1} \text {; } \\
& f_{13}=\frac{0,5 \cdot H \cdot d}{L\left(d-b_{m}+D_{m}+D_{w}\right)} ; \\
& f_{14}=\frac{d \cdot\left(D_{R}-D_{w}\right)}{L\left(d-b_{m}+D_{m}+D_{w}\right)} ; \\
& f_{15}=\frac{d}{L\left(d-b_{m}+D_{m}+D_{w}\right)} \text {; } \\
& f_{16}=\frac{d \cdot G_{p}\left(D_{p}-D_{w}+f_{w} \cdot r_{w}\right)}{L\left(d-b_{m}+D_{m}+D_{w}\right)} ; \\
& f_{33}=\frac{0,5 \cdot H}{\left(d-b_{m}+D_{m}+D_{w}\right)} \text {; } \\
& f_{34}=\frac{\left(D_{R}-D_{w}\right)}{\left(d-b_{m}+D_{m}+D_{w}\right)} ; \\
& \grave{A}_{21}=\left(\grave{I}_{\mathrm{T}} \cdot\left(\mathrm{L}-\mathrm{I}_{\mathrm{T}}\right)^{2}+\mathrm{J}_{\mathrm{T}}\right) / \mathrm{L}^{2} \text {; } \\
& \grave{A}_{22}=2 \hat{E}_{2} ; \quad \grave{A}_{23}=2 \tilde{N}_{2} \text {; } \\
& \grave{A}_{24}=2\left(\mathrm{I}_{\mathrm{T}} \cdot \mathrm{I}_{\mathrm{T}} \cdot\left(\mathrm{L}-\mathrm{I}_{\mathrm{T}}\right)-\mathrm{J}_{\mathrm{T}}\right) / \mathrm{L}^{2} \text {; } \\
& \mathrm{f}_{21}=2 \hat{\mathrm{E}}_{2} ; \mathrm{f}_{22}=2 \tilde{N}_{2} \text {; } \\
& \mathrm{f}_{31}=n \hat{E}_{3} ; \mathrm{f}_{32}=n \tilde{N}_{3} ; \\
& f_{23}=\frac{0,5 \cdot H \cdot(1-d)}{L\left(d-b_{m}+D_{m}+D_{w}\right)} ; \\
& f_{24}=-\frac{(1-d) \cdot\left(D_{R}-D_{w}\right)}{L\left(d-b_{m}+D_{m}+D_{w}\right)} ; \\
& f_{25}=\frac{(1-d)}{L\left(d-b_{m}+D_{m}+D_{w}\right)} ; \\
& f_{26}=\frac{(1-d) \cdot G_{p} \cdot\left(D_{p}-D_{w}+f_{w} \cdot r_{w}\right)}{L\left(d-b_{m}+D_{m}+D_{w}\right)} \text {; } \\
& \mathrm{f}_{35}=-\frac{1}{\left(\mathrm{~d}-\mathrm{b}_{\mathrm{m}}+\mathrm{D}_{\mathrm{m}}+\mathrm{D}_{\mathrm{w}}\right)} \text {; } \\
& f_{36}=\frac{G_{p}\left(D_{p}-D_{w}+f_{w} \cdot r_{w}\right)}{\left(d-b_{m}+D_{m}+D_{w}\right)} \text {. }
\end{aligned}
$$

In the system of equations (1) the terms $\mathrm{M}_{\mathrm{T}}, \mathrm{J}_{\mathrm{T}}$ designate the mass $(\mathrm{kg})$ of the wide span tractor (vehicle) and its moment of inertia $\left(\mathrm{kN} \cdot \mathrm{m} \cdot \mathrm{s}^{2}\right)$ relative to the axis that passes through the point $\mathrm{S}_{\mathrm{T}}$ (Fig. 2); $\mathrm{K}_{1}, \mathrm{~K}_{2}, \mathrm{~K}_{3}, \mathrm{C}_{1}, \mathrm{C}_{2}, \mathrm{C}_{3}-$ reduced deformation resistance factors of the dissipative $\left(\mathrm{kN} \cdot \mathrm{s} \cdot \mathrm{m}^{-1}\right)$ and elastic $\left(\mathrm{kN} \cdot \mathrm{m}^{-1}\right)$ members of the springing system of the wide span tractor (vehicle) and its process section;

$\mathrm{n}$ - number of carrying wheels under the process section of the wide span tractor (vehicle); $\mathrm{M}_{\mathrm{p}}, \mathrm{G}_{\mathrm{p}}-\mathrm{mass}(\mathrm{kg})$ and weight force $(\mathrm{kN})$ of the agricultural implements;

$\mathrm{L}, \mathrm{l}_{\mathrm{T}}$ - wheel base and the longitudinal coordinate of the centre of mass of the wide span tractor (vehicle) (m);

$\mathrm{H}$ - depth of soil cultivation $(\mathrm{m}) ; \mathrm{f}_{\mathrm{w}}$ - coefficient of rolling resistance of a carrying wheel of the process section;

$r_{w}$ - rolling radius of a carrying wheel; $d, b_{m}, D_{m}, D_{w}, D_{R}, D_{p}-$ design parameters, the nature of which is explained by Fig. 2.

After the Laplace transformation, the system of equations (1) will assume the following form in the operator notation:

$$
\left.\begin{array}{l}
\mathrm{K}_{11} \cdot \mathrm{z}_{1}(\mathrm{~s})+\mathrm{K}_{12} \cdot \mathrm{z}_{2}(\mathrm{~s})+\mathrm{K}_{13} \cdot \mathrm{z}_{3}(\mathrm{~s})=\mathrm{F}_{11} \cdot \mathrm{h}_{1}(\mathrm{~s})+\mathrm{F}_{12} \cdot \mathrm{h}_{2}(\mathrm{~s})+ \\
+\mathrm{F}_{13} \cdot \mathrm{h}_{3}(\mathrm{~s})+\mathrm{F}_{14} \cdot \mathrm{R}_{\mathrm{X}}(\mathrm{s})+\mathrm{F}_{15} \cdot \mathrm{R}_{\mathrm{Z}}(\mathrm{s})+\mathrm{F}_{16} \cdot \mathrm{M}_{\mathrm{R}}(\mathrm{s})+\mathrm{F}_{17}, \\
\mathrm{~K}_{21} \cdot \mathrm{z}_{1}(\mathrm{~s})+\mathrm{K}_{22} \cdot \mathrm{z}_{2}(\mathrm{~s})+\mathrm{K}_{23} \cdot \mathrm{z}_{3}(\mathrm{~s})=\mathrm{F}_{21} \cdot \mathrm{h}_{1}(\mathrm{~s})+\mathrm{F}_{22} \cdot \mathrm{h}_{2}(\mathrm{~s})+ \\
+\mathrm{F}_{23} \cdot \mathrm{h}_{3}(\mathrm{~s})+\mathrm{F}_{24} \cdot \mathrm{R}_{\mathrm{X}}(\mathrm{s})+\mathrm{F}_{25} \cdot \mathrm{R}_{\mathrm{Z}}(\mathrm{s})+\mathrm{F}_{26} \cdot \mathrm{M}_{\mathrm{R}}(\mathrm{s})+\mathrm{F}_{27}, \\
\mathrm{~K}_{31} \cdot \mathrm{z}_{1}(\mathrm{~s})+\mathrm{K}_{32} \cdot \mathrm{z}_{2}(\mathrm{~s})+\mathrm{K}_{33} \cdot \mathrm{z}_{3}(\mathrm{~s})=\mathrm{F}_{31} \cdot \mathrm{h}_{1}(\mathrm{~s})+\mathrm{F}_{32} \cdot \mathrm{h}_{2}(\mathrm{~s})+ \\
+\mathrm{F}_{33} \cdot \mathrm{h}_{3}(\mathrm{~s})+\mathrm{F}_{34} \cdot \mathrm{R}_{\mathrm{X}}(\mathrm{s})+\mathrm{F}_{35} \cdot \mathrm{R}_{\mathrm{Z}}(\mathrm{s})+\mathrm{F}_{36} \cdot \mathrm{M}_{\mathrm{R}}(\mathrm{s})+\mathrm{F}_{37},
\end{array}\right\}
$$

where: 


$$
\begin{array}{lll}
\hat{E}_{11}=\grave{A}_{11} \cdot \mathrm{s}^{2}+\mathrm{A}_{12} \cdot \mathrm{s}+\mathrm{A}_{13} ; & \mathrm{F}_{11}=\mathrm{f}_{11} \cdot \mathrm{s}+\mathrm{f}_{12} ; & \mathrm{F}_{25}=\mathrm{f}_{24} ; \mathrm{F}_{26}=\mathrm{f}_{25} ; \\
\hat{\mathrm{E}}_{12}=\grave{A}_{14} \cdot \mathrm{s}^{2} ; \hat{E}_{21}=\grave{A}_{24} \cdot \mathrm{s}^{2} ; & \mathrm{F}_{12}=\mathrm{F}_{13}=0 ; & \mathrm{F}_{31}=\mathrm{F}_{32}=0 ; \\
\hat{E}_{22}=\grave{A}_{21} \cdot \mathrm{s}^{2}+\mathrm{A}_{22} \cdot \mathrm{s}+\mathrm{A}_{23} ; & \mathrm{F}_{14}=\mathrm{f}_{13} ; \mathrm{F}_{15}=\mathrm{f}_{14} ; & \mathrm{F}_{33}=\mathrm{f}_{31} \cdot \mathrm{s}+\mathrm{f}_{32} ; \\
\hat{\mathrm{E}}_{13}=\hat{\mathrm{E}}_{23}=\hat{\mathrm{E}}_{31}=\hat{E}_{32}=0 ; & \mathrm{F}_{16}=\mathrm{f}_{15} ; \mathrm{F}_{17}=\mathrm{f}_{16} ; & \mathrm{F}_{34}=\mathrm{f}_{33} ; \mathrm{F}_{35}=\mathrm{f}_{34} ; \\
\hat{E}_{33}=\grave{A}_{31} \cdot \mathrm{s}^{2}+\mathrm{A}_{32} \cdot \mathrm{s}+\mathrm{A}_{33} ; & \mathrm{F}_{21}=\mathrm{F}_{23}=0 ; & \mathrm{F}_{36}=\mathrm{f}_{35} ; \mathrm{F}_{37}=\mathrm{f}_{36} \cdot \\
\mathrm{s}=\mathrm{d} \cdot(\mathrm{dt})^{-1} \text {-operator of differentiation;} ; & \mathrm{F}_{22}=\mathrm{f}_{21} \cdot \mathrm{s}+\mathrm{f}_{22} ; & \\
& \mathrm{F}_{24}=\mathrm{f}_{23} ; &
\end{array}
$$

The amplitude variation in the longitudinal profile of the track under the tractor's front $\left(\mathrm{h}_{1}\right)$ and rear $\left(\mathrm{h}_{2}\right)$ wheels in the area of the permanent process track and the carrying wheels of the process section $\left(\mathrm{h}_{3}\right)$ as well as the variation of the agricultural implement's tractive resistance $\left(R_{x}\right.$ and $\left.R_{z}\right)$ and the resultant moment of resistance $\left(M_{R}\right)($ Fig. 2$)$ are the main perturbations causing the vertical displacements of the wide span tractor/vehicle in the vertical-longitudinal plane.

The mentioned perturbations are the input parameters in the system of equations (2). The output parameters of the system include the amplitudes of displacement of the body of the wide span tractor/vehicle above the front $\left(\mathrm{z}_{1}\right)$ and rear $\left(\mathrm{z}_{2}\right)$ wheels and the oscillations of its process section body $\left(\mathrm{z}_{3}\right)$.

Considering the response of the wide span tractor/vehicle to the perturbing actions, the transfer functions chosen for the analysis will be expressed as follows:

$$
\begin{aligned}
& \mathrm{W}_{1}(\mathrm{~s})=\mathrm{D}_{11} / \mathrm{D}_{0} \quad-\text { transfer function of the longitudinal profile of the track under the rear wheels of the wide span tractor } \\
& \text { (vehicle) relative to the oscillations of the rear part of its body; } \\
& \mathrm{W}_{2}(\mathrm{~s})=\mathrm{D}_{12} / \mathrm{D}_{0} \quad-\text { transfer function of the longitudinal profile of the track under the front wheels of the wide span tractor } \\
& \text { (vehicle) relative to the oscillations of the front part of its body; } \\
& \mathrm{W}_{3}(\mathrm{~s})=\mathrm{D}_{13} / \mathrm{D}_{0} \quad-\text { transfer function of the longitudinal profile of the track under the carrying wheels of the wide span } \\
& \text { tractor (vehicle) process section relative to the oscillations of its body; } \\
& \mathrm{W}_{4}(\mathrm{~s})=\mathrm{D}_{14} / \mathrm{D}_{0} \quad-\text { transfer function of the horizontal resistance reaction of the agricultural implement relative to the } \\
& \text { oscillations of the rear part of the body of the wide span tractor (vehicle); } \\
& \mathrm{W}_{5}(\mathrm{~s})=\mathrm{D}_{15} / \mathrm{D}_{0} \quad-\text { transfer function of the vertical resistance reaction of the agricultural implement relative to the } \\
& \text { oscillations of the rear part of the body of the wide span tractor (vehicle), }
\end{aligned}
$$

where $\mathrm{D}_{0}, \mathrm{D}_{11}, \ldots \mathrm{D}_{15}$ - determinants defined as follows:

$$
\begin{aligned}
& D_{0}=a_{6} \cdot s^{6}+a_{5} \cdot s^{5}+a_{3} \cdot s^{3}+a_{2} \cdot s^{2}+a_{1} \cdot s^{1}+a_{0} ; \\
& D_{11}=\left(\grave{A}_{11} \cdot s^{2}+\grave{A}_{12} \cdot s^{1}+\grave{A}_{13}\right) \cdot\left(\mathrm{f}_{21} \cdot s^{1}+\mathrm{f}_{22}\right) \cdot\left(\grave{A}_{11} \cdot s^{2}+\grave{A}_{12} \cdot s^{1}+\grave{A}_{13}\right) ; \\
& D_{12}=\left(\grave{A}_{31} \cdot s^{2}+\grave{A}_{32} \cdot s^{1}+\grave{A}_{33}\right) \cdot\left(f_{11} \cdot s^{1}+f_{12}\right) \cdot\left(\grave{A}_{21} \cdot s^{2}+\grave{A}_{22} \cdot s^{1}+\grave{A}_{23}\right) ; \\
& D_{13}=\left(f_{31} \cdot s^{1}+f_{32}\right) \cdot\left(\grave{A}_{14} \cdot s^{2} \cdot \grave{A}_{24} \cdot s^{2}-\left(\grave{A}_{11} \cdot s^{2}+\grave{A}_{12} \cdot s^{1}+\grave{A}_{13}\right) \cdot\left(\grave{A}_{21} \cdot s^{2}+\grave{A}_{22} \cdot s^{1}+\grave{A}_{23}\right) ;\right. \\
& D_{14}=\left(\grave{A}_{31} \cdot s^{2}+\grave{A}_{32} \cdot s^{1}+\grave{A}_{33}\right) \cdot\left(\left(\grave{A}_{11} \cdot s^{2}+\grave{A}_{12} \cdot s^{1}+\grave{A}_{13}\right) \cdot f_{23}-A_{24} \cdot s^{2} \cdot f_{13}\right) \text {; } \\
& D_{15}=\left(\grave{A}_{31} \cdot s^{2}+\grave{A}_{32} \cdot s^{1}+\grave{A}_{33}\right) \cdot\left(\left(\grave{A}_{11} \cdot s^{2}+\grave{A}_{12} \cdot s^{1}+\grave{A}_{13}\right) \cdot f_{24}-A_{24} \cdot s^{2} \cdot f_{14}\right) \text {; }
\end{aligned}
$$

herein:

$$
\begin{aligned}
& a_{6}=\left(A_{11} \cdot A_{21}-A_{14} \cdot A_{24}\right) \cdot A_{31} ; \\
& \grave{a}_{5}=\left(\grave{A}_{12} \cdot \grave{A}_{21}+A_{11} \cdot A_{22}\right) \cdot \grave{A}_{31}+\left(\grave{A}_{11} \cdot \grave{A}_{21}-A_{14} \cdot A_{24}\right) \cdot \grave{A}_{32} ; \\
& \grave{a}_{4}=\left(\grave{A}_{13} \cdot \grave{A}_{21}+A_{12} \cdot A_{22}+\grave{A}_{11} \cdot \grave{A}_{23}\right) \cdot \grave{A}_{31}+\left(\grave{A}_{12} \cdot \grave{A}_{21}+A_{11} \cdot A_{22}\right) \cdot \grave{A}_{32}+\left(\grave{A}_{11} \cdot \grave{A}_{21}-A_{14} \cdot A_{24}\right) \cdot \grave{A}_{33} ; \\
& \grave{a}_{3}=\left(\grave{A}_{13} \cdot \grave{A}_{22}+A_{12} \cdot A_{23}\right) \cdot \grave{A}_{31}+\left(\grave{A}_{13} \cdot \grave{A}_{21}+A_{12} \cdot A_{22}+\grave{A}_{11} \cdot \grave{A}_{23}\right) \cdot \grave{A}_{32}+\left(\grave{A}_{12} \cdot \grave{A}_{21}+A_{11} \cdot A_{22}\right) \cdot \grave{A}_{33} ; \\
& \grave{a}_{2}=\grave{A}_{13} \cdot \grave{A}_{23} \cdot \grave{A}_{31}+\left(\grave{A}_{13} \cdot \grave{A}_{22}+A_{12} \cdot A_{23}\right) \cdot \grave{A}_{32}+\left(\grave{A}_{13} \cdot \grave{A}_{21}+A_{12} \cdot A_{22}+\grave{A}_{11} \cdot \grave{A}_{23}\right) \cdot \grave{A}_{33} ; \\
& \grave{a}_{1}=\grave{A}_{13} \cdot \grave{A}_{23} \cdot \grave{A}_{32}+\left(\grave{A}_{13} \cdot \grave{A}_{22}+A_{12} \cdot A_{23}\right) \cdot \grave{A}_{33} ; \\
& \grave{a}_{0}=\grave{A}_{13} \cdot \grave{A}_{23} \cdot \grave{A}_{33} ;
\end{aligned}
$$

After substituting the above determinants into the transfer functions $\mathrm{W}_{1}-\mathrm{W}_{5}$, the general form of the latter will appear as follows:

$$
W_{3}(s)=\frac{b_{5} \cdot s^{5}+b_{4} \cdot s^{4}+b_{3} \cdot s^{3}+b_{2} \cdot s^{2}+b_{1} \cdot s^{1}+b_{0}}{\grave{a}_{6} \cdot s^{6}+\grave{a}_{5} \cdot s^{5}+\grave{a}_{4} \cdot s^{4}+\grave{a}_{3} \cdot s^{3}+\grave{a}_{2} \cdot s^{2}+\grave{a}_{1} \cdot s^{1}+a_{0}},
$$

where $b_{0} \ldots b_{6}$ - coefficients, the nature of which is stipulated by the functional relationship between the design and process parameters of the investigated wide span tractor (vehicle) and the perturbing action characteristics. 
It can be concluded, after the analysis of the mathematical model (1), that the dynamics of the vertical oscillations of the wide span tractor/vehicle depends on a number of its design parameters. The parameters of the carrying wheel pneumatic tyre, in particular its stiffness coefficient, are the most important of them. In the process of mathematical modelling of the vertical oscillations of the wide span tractor (vehicle) of our design, which was taken as the physical subject of research, three practicable options were given consideration with regard to the standard size of the tyres on its wheels: 1) 11.2R20; 2) 11.2R32; 3) 9.5R42.

The stiffness of the tyre on the i-th carrying wheel of the wide span tractor (vehicles) can be found with the use of the established formula of Heideckel:

$$
C_{i}=\pi \cdot \rho_{w} \cdot \sqrt{D \cdot B}
$$

where D - static tyre diameter $(\mathrm{m}) ; \mathrm{B}$ - tyre section width $(\mathrm{m}) ; \rho_{\mathrm{w}}-$ tyre air pressure $(\mathrm{Pa})$.

\section{Results and Discussion}

As a result of the mathematical modelling, it has been established that the difference between the design AFRs and PFRs of the above-mentioned tyre options is virtually negligible (Graphs 1-3, Fig. 3), despite the certain difference in the values of their coefficients of stiffness $\mathrm{C}_{2}$. At the same time, the characteristics of the response of the wide span tractor /vehicle to the variation of irregularities in the longitudinal profile of the track in the area of the permanent process track to a considerable extent depend on the perturbing action frequency. Thus, at frequencies of up to $7.0 \mathrm{~s}^{-1}$ the effect of this parameter is virtually unnoticeable. At $\omega>7.0 \mathrm{~s}^{-1}$, the rise of the tyre's stiffness causes the lowering of the AFR together with the shifting of the resonance peaks to the side of higher frequencies (see Fig. 3 a). For the tyre size options under consideration, the latter are concentrated within a range of $\omega=10-11 \mathrm{~s}^{-1}$. And that is exactly the most undesirable range of frequencies for the variation of the permanent process track's longitudinal profile irregularities, because in this range the dynamic system (i.e. the wide span tractor (vehicle) amplifies the input perturbation at a gain rate of over 6 . The dynamics of the vertical oscillations of the wide span tractor (vehicle) cannot be improved even by raising the stiffness of its tyres to $450 \mathrm{kN} \cdot \mathrm{m}^{-1}$ (Graph 5, Fig. 3 a). On the other hand, its possible reduction down to $150 \mathrm{kN} \cdot \mathrm{m}^{-1}$ lowers the AFR and also displaces its resonance peaks to the side of low frequencies (Graph 6, Fig. 3 a). At the same time, the dispersion of oscillation of the permanent process track irregularities within a frequency range of $\omega=13-15 \mathrm{~s}^{-1}$ is the most desirable for all the three wheel tyre options under consideration, because it brings the characteristics into proximity with the ideal ones.

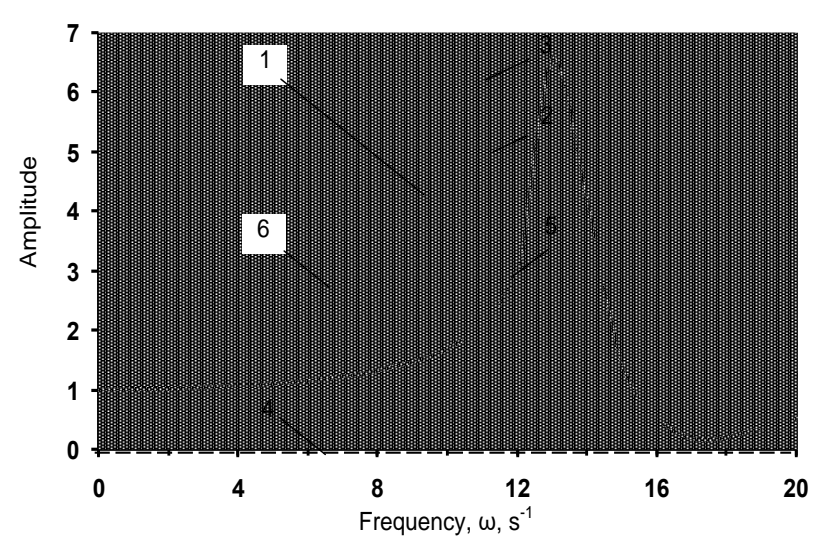

a)

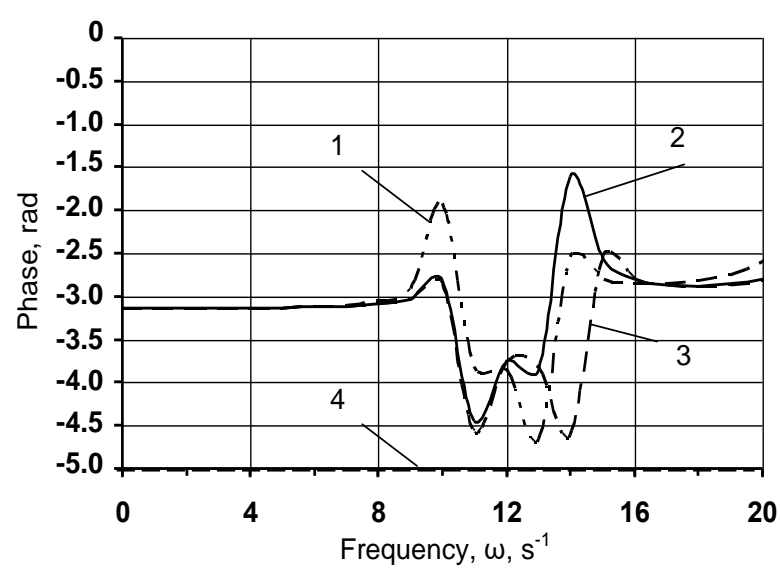

b)

Fig. 3. AFR (a) and PFR (b) characteristics of the response of the body above the rear wheels of the wide span tractor (vehicle) to the track's longitudinal profile variation, for tyres with different stiffness factors: 1) $11.2 \mathrm{R} 20\left(\mathrm{C}_{2}=254 \mathrm{kN} \cdot \mathrm{m}^{-1}\right)$; 2) $11,2 \mathrm{R} 32\left(\mathrm{C}_{2}=292 \mathrm{kN} \cdot \mathrm{m}^{-1}\right)$; 3) $9.5 \mathrm{R} 42\left(\mathrm{C}_{2}=296 \mathrm{kN} \cdot \mathrm{m}^{-1}\right)$; 4a ideal characteristics;

$$
\text { 5) } \mathrm{C}_{2}=450 \mathrm{kN} \cdot \mathrm{m}^{-1} \text {; 6) } \mathrm{C}_{2}=150 \mathrm{kN} \cdot \mathrm{m}^{-1}
$$

As regards the desirable response of the dynamic system to the considered perturbation, the significant increase of the coefficient of stiffness of the wide span tractor's tyres will be effective only in the event that the dispersion of oscillations of the permanent process track irregularities remains within a frequency range of $\omega=0 \ldots 8 \mathrm{~s}^{-1}$ and $\omega=16 \ldots 20 \mathrm{~s}^{-1}$. When the perturbation frequency is below $8 \mathrm{~s}^{-1}$, the vertical oscillations of the wide span tractor (vehicle) very little depend on the magnitude of the coefficient of stiffness of its tyres. Also, it is desirable in case of the considered three options of its wheel tyres that the dispersion of the permanent process track's longitudinal profile irregularities remains within a frequency range of $\omega=13-15 \mathrm{~s}^{-1}$, where the dynamic system under consideration reacts almost not at all to the input perturbation. In practice this condition can be met by applying the corresponding technology of shaping the ruts of the 
permanent process track or by changing the stiffness of the pneumatic tyres through the selection of such an air pressure in them, which will ensure the minimum response of the dynamic system to the input perturbation (Fig. 4).

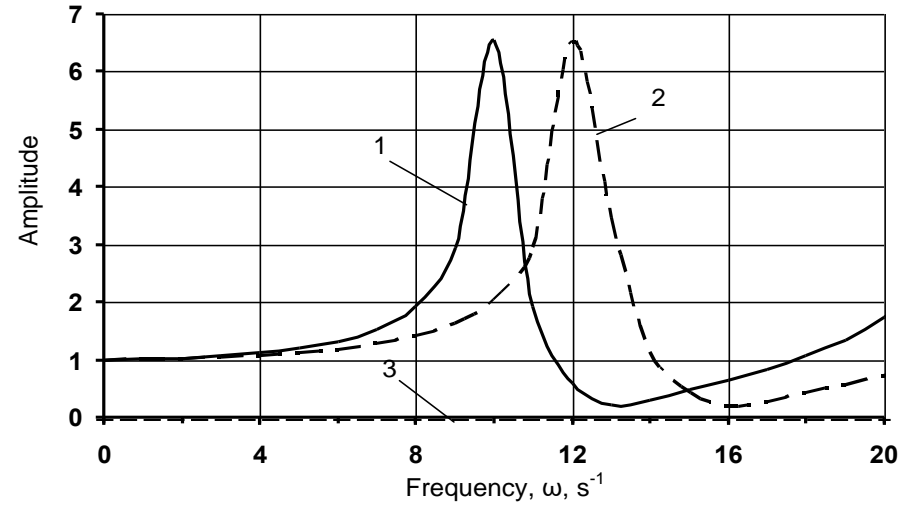

a)

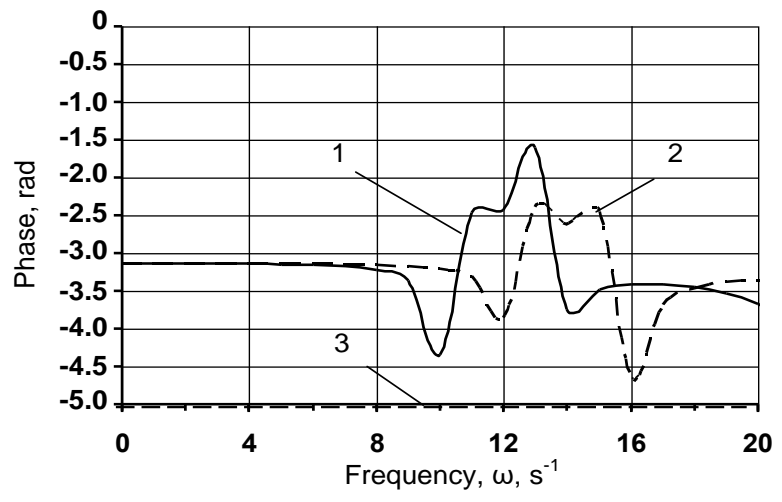

b)

Fig. 4. AFR (a) and PFR (b) characteristics of the response of the wide span tractor (vehicle) to the track's longitudinal profile variation, for $11.2 \mathrm{R} 20$ tyres at different air pressures: 1) $\mathrm{p}_{\mathrm{w}}=160 \mathrm{kPa}$; $) \mathrm{p}_{\mathrm{w}}=240 \mathrm{kPa}$; 3 ) ideal characteristics

It follows from the analysis of the experimental data on the shaping of the longitudinal profiles of the ruts of the permanent process track created on uncultivated ground by the wheeled and tracked running gear of tractors that, although the longitudinal profiles of the tracks may have somewhat similar non-uniformity, their inner patterns are different. The results of the analysis of the normalized correlation functions (Fig. 5) show that the longitudinal profile of the track rut created by the wheeled tractor has the lowest-frequency characteristic. Its correlation distance is about $0.57 \mathrm{~m}$, which is 8 times greater, when compared to the longitudinal profile of the track rut created by the caterpillar tractor. Even when compared to the original uncultivated agricultural background, the running gear of the caterpillar tractor generates a higher-frequency longitudinal profile of the rut with a pronounced periodic component. The source of generation of the latter can be found in the track pitch $(17 \mathrm{~cm})$, which is virtually equal to the wavelength of the longitudinal track profile irregularities, that is $17.4 \mathrm{~cm}$. The progression of a wheeled tractor on the ruts laid down by a caterpillar tractor generates the oscillations of its body with a higher-frequency characteristic as compared to its travelling on its own track. In the former case the correlation time did not exceed $0.16 \mathrm{~s}$, in the latter one it rose to $1.5 \mathrm{~s}$.

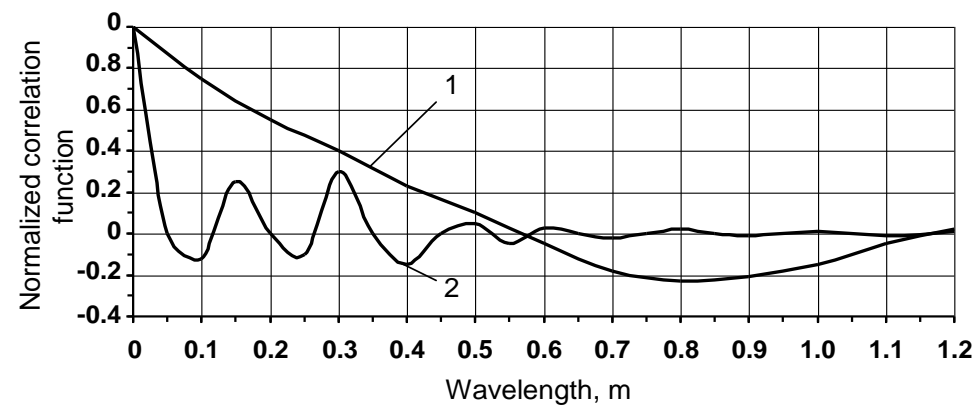

Fig. 5. Normalized correlation functions of longitudinal profiles of permanent process track ruts created on uncultivated agricultural background by the running gear of wheeled (1) and tracked (2) tractors

Basing on the above-stated analysis, it is possible to conclude that the reduction of the stiffness of tyres of the wide span tractor (vehicle) in case of a lower-frequency range of the permanent process track rut's longitudinal profile irregularities will be generally effective. For example, when the tyre stiffness of the wide span tractor (vehicle) under consideration is reduced to $150 \mathrm{kN} \mathrm{m}^{-1}$ (Graph 6, Fig. $3 \mathrm{a}$ ), the desirable frequency range of the process track's longitudinal profile irregularities will shift to lower values of $\omega=9-13 \mathrm{~s}^{-1}$.

The dynamics of the vertical oscillations of the wide span tractor (vehicle) process section is defined, according to (1), first of all by its carrying wheel tyre stiffness and its operating mass $\mathrm{M}_{\mathrm{p}}$. The mathematical modelling has shown that the increase of the operating mass $\mathrm{M}_{\mathrm{p}}$ from $300 \mathrm{~kg}$ to $500 \mathrm{~kg}$ causes the undesirable rise of the AFR characteristic of the response by the process section to the variation of the track's profile together with the shift of the resonance peaks to the lower frequency side (Graphs 2 and 3, Fig. 6 a). If that is complemented with the significant reduction of the carrying wheel tyre stiffness factor to $25 \mathrm{kN} \cdot \mathrm{m}^{-1}$, i.e. by factor of 4 (Graph 5, Fig. 6 a), then the AFR resonance peaks will shift even more to the side of lower frequencies. Meanwhile, the rate of amplification of the input perturbation by the dynamic system at a resonance frequency will be reduced only by factor of 2 . Only at frequencies over $13 \mathrm{~s}^{-1}$, the AFR becomes less than a unity and the characteristics move closer to the ideal ones. By contrast, the increase of the stiffness of the 
carrying wheel tyres to $200 \mathrm{kN} \cdot \mathrm{m}^{-1}$ (Graph 1, Fig. 6a) results in the situation, where within a low-frequency range (up to $\omega=8 . .10 \mathrm{~s}^{-1}$ ) the process section responds to the input perturbation at a virtually insignificant gain rate; only at a frequency of $\omega=18 \mathrm{~s}^{-1}$ the gain rate reaches a level of 2 .

When the variation of the permanent process track's longitudinal profile irregularities stays within a frequency range of $\omega=13-15 \mathrm{~s}^{-1}$, which is the most desirable for the motion of the wide span tractor (vehicle), as it was mentioned earlier, the change of the process section carrying wheel tyre stiffness results in the following. At a tyre stiffness factor of $\mathrm{C}_{3}=200 \mathrm{kN} \cdot \mathrm{m}^{-1}$ (Graph 1, Fig. 6 a), the AFR has an input perturbation amplification rate of not more than 1.5. The further increase of the tyre stiffness up to the use of a bare band brings the AFR into proximity to 1, i.e. the dynamic system copies the track's longitudinal profile irregularities. The reduction of the tyre stiffness from $200 \mathrm{kN} \cdot \mathrm{m}^{-1}$ to $100 \mathrm{kN} \cdot \mathrm{m}^{-1}$ (Graph 2, Fig. 6 a) within the mentioned frequency range raises the AFR to 3, distancing it from the ideal one. The further reduction of the tyre stiffness from $100 \mathrm{kN} \cdot \mathrm{m}^{-1}$ to $50 \mathrm{kN} \cdot \mathrm{m}^{-1}$ (Graph 4, Fig. 6 a) makes the dynamics of motion of the process section in the vertical plane within the mentioned frequency range even worse. Only after bringing the tyre stiffness factor down to $25 \mathrm{kN} \cdot \mathrm{m}^{-1}$, the characteristics in a frequency range of $\omega=13-15 \mathrm{~s}^{-1}$ approximate the ideal ones (Graph 5, Fig. 6 a).

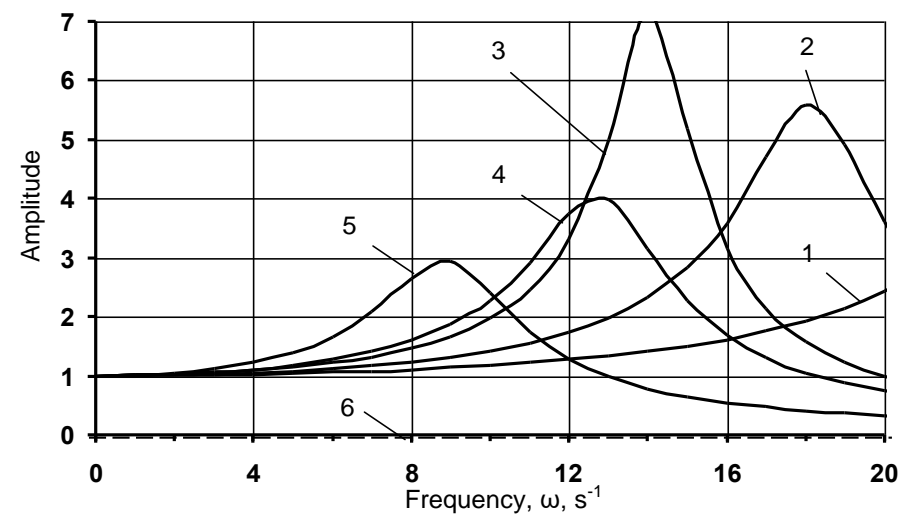

a)

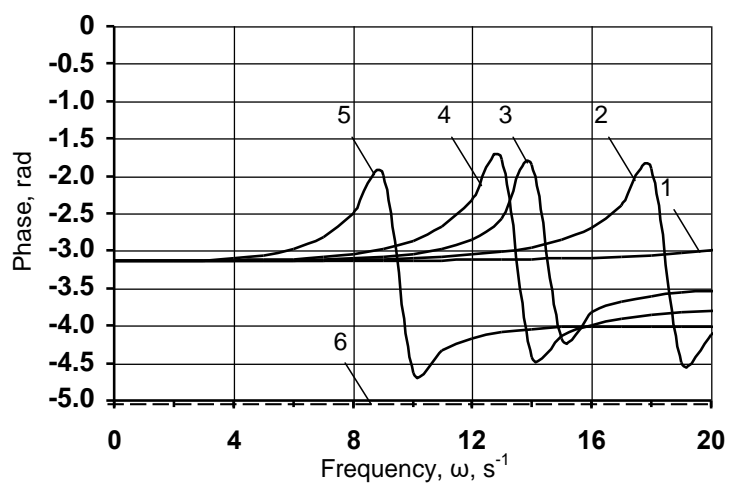

b)

Fig. 6. AFR (a) and PFR (b) characteristics of the response of the wide span tractor (vehicle) process section to the track's longitudinal profile variation, at different values of mass $\left(M_{p}\right)$ and carrying wheel tyre stiffness factor $\left.\left(C_{3}\right): 1\right) M_{p}=300 \mathrm{~kg}$; $\mathrm{C}_{3}=200 \mathrm{kN} \cdot \mathrm{m}^{-1}$; 2) $\left.\left.\mathrm{M}_{\mathrm{p}}=300 \mathrm{~kg} ; \mathrm{C}_{3}=100 \mathrm{kN} \cdot \mathrm{m}^{-1} ; 3\right) \mathrm{M}_{\mathrm{p}}=500 \mathrm{~kg} ; \mathrm{C}_{3}=100 \mathrm{kN} \cdot \mathrm{m}^{-1} ; 4\right) \mathrm{M}_{\mathrm{p}}=300 \mathrm{~kg} ; \mathrm{C}_{3}=50 \mathrm{kN} \cdot \mathrm{m}^{-1}$; 5) $\left.\mathrm{M}_{\mathrm{p}}=300 \mathrm{~kg} ; \mathrm{C}_{3}=25 \mathrm{kN} \cdot \mathrm{m}^{-1} ; 6\right)$ ideal characteristics

Proceeding from the above-stated analysis, it can be concluded that increasing the operating mass of the process section is not advisable. When the main dispersion spectrum of the permanent process track irregularities is concentrated in a higher-frequency range of $\omega=13-15 \mathrm{~s}^{-1}$, the coefficient of stiffness of its tyres must not exceed $25 \mathrm{kN} \cdot \mathrm{m}^{-1}$. Alternatively, the use of process section carrying wheels with a tyre stiffness factor of about $200 \mathrm{kN} \cdot \mathrm{m}^{-1}$ and higher is desirable with respect to the section's dynamics of motion in the vertical plane.

The characteristic of the response to the variation of the tractive resistance of the agricultural implement on the process section of the wide span tractor (vehicle) (Fig. 7) to a considerable extent depends on the position of the hitch mechanism relative to the axis of the wide span tractor (vehicle) rear wheels (design parameter $b_{m}$, Fig. 2). It follows from the analysis of the obtained AFR that the worst characteristics are observed, when the hitch mechanism of the wide span tractor (vehicle) is situated in the space between its wheels (Graph 3, Fig. 7 a). In that case, the perturbation gain rate at a resonance frequency of $\omega=11 \mathrm{~s}^{-1}$ reaches almost 20 for the tractive resistance component $R_{x}$, and 30 for the vertical component $\mathrm{R}_{\mathrm{z}}$. The most acceptable, with respect to the dynamics of the vertical oscillations of the wide span tractor (vehicle), will be the positioning of the hitch mechanism of the wide span tractor (vehicle) behind the rear wheels of the wide span tractor (vehicle), since that arrangement brings the actual AFRs into proximity to the ideal ones (Graph 1, Fig. 7 a). In that case, considering an oscillation frequency range of $0 \ldots 14.0 \mathrm{~s}^{-1}$, which is characteristic of the majority of agricultural implements, each $1 \mathrm{kN}$ is associated with 5 to $35 \mathrm{~mm}$ of the amplitude of the vertical oscillations of the wide span tractor (vehicle) (Graph 1, Fig. 7 a).

As regards the phase shift of the dynamic system's response to the perturbations in the tractive resistance of the agricultural implement, the PFR characteristic is virtually independent of the design parameter $b_{\mathrm{H}}$ (Fig. 7 b). Moreover, the observed tendency of the actual PFRs to the ideal ones at a resonance frequency of $\omega=11 \mathrm{~s}^{-1}$ is desirable. 


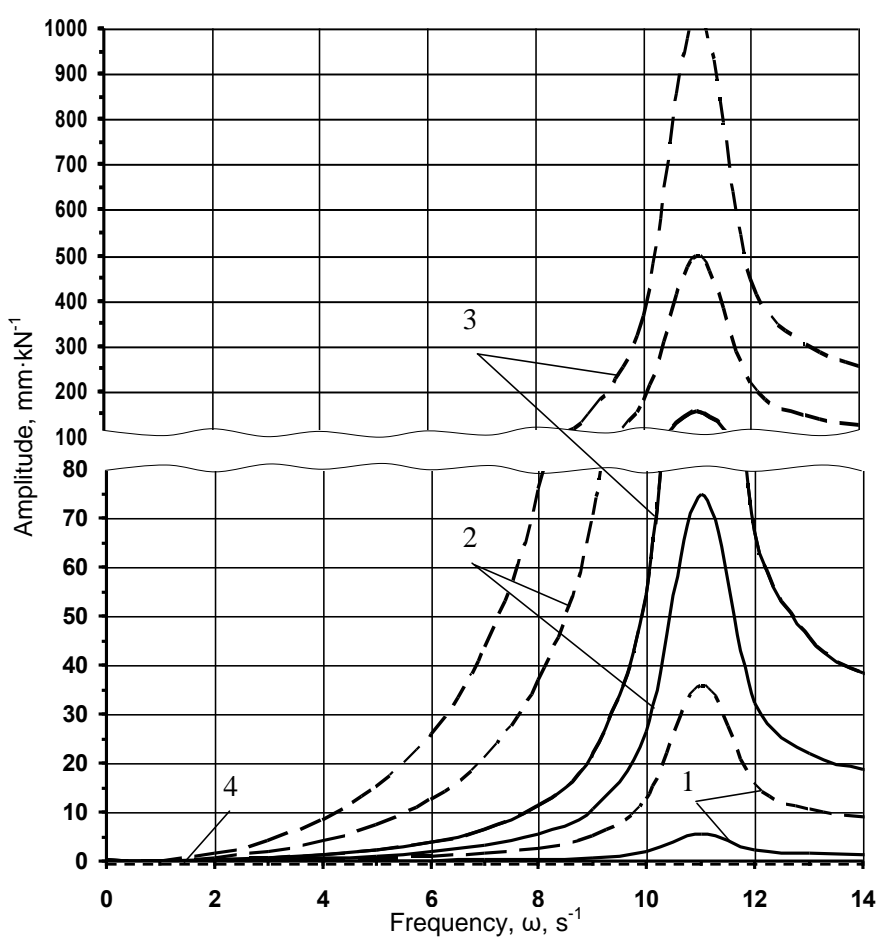

a)

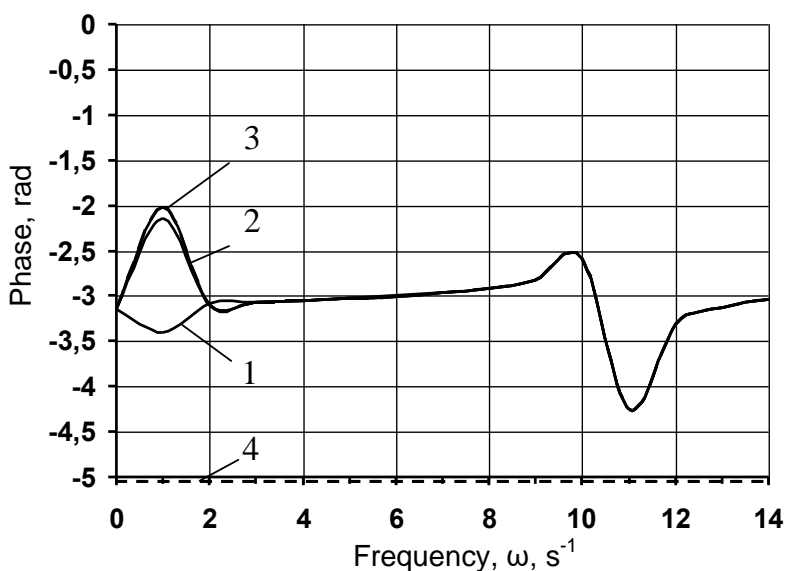

b)

Fig. 7. FR (a) and PFR (b) characteristics of response of wide span tractor (vehicle) to variation of horizontal $R_{x}(-)$ and vertical $R_{\mathrm{z}}$ (-----) components of the tractive resistance of agricultural implement, for different positions of hitch mechanism (design parameter $b_{m}$ ): 1) $\left.\left.\left.b_{m}=1 m ; 2\right) b_{m}=0 m ; 3\right) b_{m}=-1 m ; 4\right)$ ideal characteristics

\section{Conclusions}

The smoothness of movement of the wide span tractor (vehicle) as a dynamic system travelling on the ruts of the permanent process track depends to a considerable extent on the characteristics of the track's longitudinal profile irregularities. The required inner pattern of the longitudinal profile of the laid-down process track can be obtained in practice with the use of an adequate technology of its shaping. The quality of the dynamic system's response to the input perturbations, which comprise the permanent process track's longitudinal profile irregularities and the variation of the soil's tractive resistance, depends on the configuration as well as the design and other parameters of the wide span tractor (vehicle). A considerable effect on the smoothness of movement of the latter has the stiffness of its carrying wheel tyres, the value of which can be controlled, within certain limits, by changing the air pressure in the tyres. The improved dynamics of motion of the process section of the wide span tractor (vehicle) is observed, when the stiffness of the tyres on its carrying wheels is increased and its operating mass is reduced.

\section{References}

[1] Bindi, I.; Blackwell, P., Riethmuller, G.; Davies, S.; Whitlock, A. \& Neale, T. (2013). This Controlled Traffic Farming Technical Manual. It updates the Tramline Farming Systems: Technical Manual Bulletin 4607. Published by the Department of Agriculture and food, Western Australia. 78 p.

[2] Blackwell, P.; McKenzie, D; Webb, B.; Lemon, J.; Barber, P.; Fretwell, G.; Bignell, G. \& Moffat, N. (2004, a). Compaction of heavy soils by cropping traffic and estimated benefits of tramline farming. Agribusiness Crop Updates, Perth.

[3] Blackwell, P.; Webb, B.; Fretwell, G.; Moffat, N. \& Chappel, L. (2004, b). Tramlines for less fuel use, pollution and greener farming! Agribusiness Crop Updates, Perth.

[4] Bochtis, D.D.; Sørensen, C.G.; Busatob, P.; Hameed, I.A.; Rodias, E.; Green, O. \& Papadakis, G. (2010). Tramline establishment in controlled traffic farming based on operational machinery cost. Biosystems Engineering, Vol. 107, No. 3, pp. 221-231, ISSN 1537-5110, DOI: 10.1016/j.biosystemseng.2010.08.004.

[5] Bulgakov, V.; Adamchuck, V., Kuvachov, V., Ivanovs, S. (2017). Investigation of technological properties of wide sapn tractors for controlled trafic farming. Proceedings of $16^{\text {th }}$ Int. Sci. Conf. Engineering for Rural Development, 24.26.05.2017, ISSN 1691-5976, pp. 303-308, Jelgava, DOI: 10.22616/ERDev2017.16.N060. 
[6] Chamen, W.C.T. (2000). A New Methodology For Weed Control And Cereal Crop Production Based On Wide Span Vehicles And Precision Guidance: Biotrac / 4th EWRS Workshop on Physical Weed Control, , 20-22 March 2000. pp. 51-55, Elspeet, The Netherlands.

[7] Chamen T. (2015). Controlled traffic farming - from world wide research to adoption in Europe and its future prospects. Acta Technologica Agriculturae Nitra 3, pp. 64-73.

[8] Evans, T.A.; Dawes, T.Z.; Ward, P.R. \& Lo, N. (2011). Ants and termites increase crop yield in a dry climate. Nature Communications, 2:262 doi: 10.1038/ncomms 1257.

[9] Evans, F.; Hashim, A. \& Diggle, A. (2009). Risk of glysophate resistance in wide-row lupin cropping systems. 2009 Agribusiness Crop Updates, Perth.

[10] Onal I. (2012). Controlled Traffic farming and Wide Span Tractors. Journal of Agricultural Machinery Science Vol. 8, No 4, pp. 353-364.

[11] Pedersen, H.H. (2011). Harvest Capacity Model for a Wide Span Onion Bunker Harvester. Automation and System Technology in Plant Production, CIGR section V \& NJF section VII conference, pp. 27-36.

[12] Pedersen, H.H.; Sørensen, C.G.; Oudshoorn, F.W. \& McPhee, J.E. (2013). User requirements for a Wide Span Tractor for Controlled Traffic Farming. International Commission of Agricultural and Biological Engineers, Section V. CIOSTA XXXV Conference "From Effective to Intelligent Agriculture and Forestry", 3-5 July 2013. pp. 134136, Billund, Denmark.

[13] Popp, K., Schiehler, W. (2010). Ground Vehicle Dynamics. Springer. ISBN 978-3-540-68553-1.

[14] Rajamani, R. (2012). Vehicle dynamics and control. Springer. ISBN 978-1-4614-1433-9.

[15] Tullberg J.N. (2000), Wheel traffic effects on tillage draft. Journal of Agricultural Engineering Research, Vol. 75, No. 4, pp. 375-382, ISSN 0021-8634, DOI: 10.1006/jaer.1999.0516.

[16] Tullberg, J.N.; Yule, D.F. \& McGarry D. (2007). Controlled traffic farming -from research to adoption in Australia. Soil and Tillage Research, Vol. 97, No. 2, pp. 272-281, ISSN 0167-1987, DOI: 10.1016/j.still.2007.09.007.

[17] Tullberg, J.N. (2013). CTF impacts: Environment = Economic. ISTRO Controlled Traffic Conference 2013, Toowoomba.

[18] Tullberg, J.N.; Ziebarth, P.J. \& Yuxia, Li. (2001). Tillage and traffic effects on runoff. Australian Journal of Soil Research, Vol. 39, pp. 249-257.

[19] Tullberg, J.N.; McHugh, A.; Ghareel Khabbaz, B.; Scheer, C. \& Grace, P. (2011). Controlled Traffic/permanent bed farming reduces GHG emissions. Proceedings of 5th World Congress of Conservation Agriculture incorporating 3rd Farming Systems Design Conference, Brisbane.

[20] Webb, B., Blackwell, P., Riethmuller, G. \& Lemon, J. (2004). Tramline farming systems: technical manual, Bulletin 4607, Department of Agriculture, Western Australia.

[21] Wong, J.Y. (2008). Theory of ground vehicles. John Wiley \& Sons, ISBN 978-0-470-17038-0. 